\title{
A Model for the Elastic Modulus of Hydrate-Bearing Sediments
}

\author{
Xuhui Zhang* \\ Institute of Mechanics, Chinese Academy of Sciences \\ Beijing, China \\ Lele Liu \\ Qingdao Institute of Marine Geology \\ Qingdao, China \\ Junbing Zhou, Xiaobing Lu and Shuyun Wang \\ Institute of Mechanics, Chinese Academy of Sciences \\ Beijing, China \\ Changling Liu and Yuguang Ye \\ Qingdao Institute of Marine Geology \\ Qingdao, China
}

\begin{abstract}
A model for the elastic modulus of hydrate-bearing sediment (HBS) is presented considering the variation of the hydrate saturation and hydrate occurrence mode. The model is based on the classical series and parallel modes, introducing a parameter of statistical force transfer paths among particles in HBS. Macro-triaxial compression tests and micro X-ray computed tomography (CT) observations of HBS in the gas-saturated formation mode were conducted. The applicability of the model was checked through the comparison between tests and theoretical results.
\end{abstract}

\section{INTRODUCTION}

Natural gas hydrate, a compound of methane molecules and water molecules, extensively exists in marine and permafrost sediments. Hydrate-bearing sediment (HBS) is a new kind of multiphase composite geotechnical material that consists of the gas hydrate, soil skeleton, and pore fluid of gas and water. The mechanical properties of HBS are the basic parameters for the analysis of soil deformation and failures during hydrate exploration and exploitation.

Many studies have been conducted in the laboratory by triaxial compression tests to obtain the mechanical data of HBS (Masui et al., 2008; Hyodo et al., 2007; Hyodo, 2013; Miyazaki et al., 2010; Miyazaki and Masui, 2011; Waite et al., 2008, 2009; Winters, 1999; Winters et al., 2004; Yun et al., 2007; Zhang et al., 2012a; Song et al., 2010). Different methodologies for sampling methane hydrate (dissolved gas method, partial water saturation method, ice-seeding method, hydrate premixing method) resulted in different hydrate occurrence modes in the pores of sediment (Ecker et al., 2000; Winters et al., 2004). By the most adopted dissolved gas method, heterogeneous nucleation occurs on the particle surface, subsequently grows into the pore space (pore-filling type), and goes to the final cementation with grains (grain-cementation type). The most pronounced increase in strength occurs when the hydrate saturation exceeds $40 \%$. The explanation is that once hydrate saturation exceeds the critical value, the hydrate occurrence mode transfers from the pore-filling type to the grain-cementation type.

\section{*ISOPE Member.}

Received January 13, 2015; revised manuscript received by the editors August 24, 2015. The original version was submitted directly to the Journal.

KEY WORDS: Hydrate-bearing sediment, series and parallel model, elastic modulus, hydrate occurrence, hydrate saturation.
The elastic modulus of HBS is the main parameter for the evaluation of deformation. The relationship among the hydrate saturation, acoustic wave speed, and elastic modulus is required for both the resource assessment and the detection of dissociation front during the production of gas hydrate. The characteristics of the multiphase media (such as the hydrate saturation, sediment type, and hydrate formation mode) affect the acoustic wave speed and the elastic parameters of HBS. The theoretical relations were divided into two types (Lee et al., 1996; Lee and Collett, 2006; Wood, 1941): (a) the relation between the hydrate saturation and the acoustic wave speed of HBS and (b) the relation between the acoustic wave speed of HBS and the mechanical parameters (such as elastic modulus and shear modulus).

In the time-average model, the acoustic wave speed of HBS was taken as the weighted sum of that of each constituent. However, the effect of the cementation of hydrate was not considered in the model. Lee et al. (1996) combined the time-average method with the Wood equation (Wood, 1941). The weighted equation could predict well the elastic properties of HBS containing gas, but it was empirical. Lee and Collett (2006) presented a method to forecast the wave speed of underconsolidated HBS. The advantage of the model based on effective medium theory is that it can effectively predict the elastic properties of loose and gas-containing HBS. A linear relationship considering three phases (ice, hydrate, and soil matrix) was presented by Zhang et al. (2012a) to fit the elastic modulus of HBS. However, the predicted hydrate saturations by different models differ much from each other because of different hydrate occurrence modes in the pores of HBS.

This paper presents a model for the elastic modulus of HBS that is related to the hydrate saturation and hydrate occurrence mode. This model is based on the classical series and parallel modes and includes the force transfer path among particles in HBS. The model is validated by the triaxial test results, and its application is also discussed. 


\section{THE METHODOLOGIES OF ELASTIC MODULUS}

From a viewpoint of micromechanics, the mechanical properties of HBS are determined by the volume fraction and the mechanical properties of each phase as well as the size, shape, and arrangement of micrograins, etc. The hydrate saturation and hydrate occurrence mode in HBS are the main factors.

\section{Mixed Model for Anisotropic Multiphase Composite Material}

The mixed model of elastic modulus for a composite material is based on statistical mathematics. It relates the elastic modulus and the volume fraction of each phase (Hashin, 1962; Hashin and Shtrikman, 1963; Dvorkin et al., 1999, 2000).

The general expression for the model of multiphase media is as follows:

$E_{\mathrm{eff}}=f\left(V_{1}, V_{2}, \ldots, V_{i}, E_{1}, E_{2}, \ldots, E_{i}\right)$

where $E_{\text {eff }}$ is the total effective elastic modulus, $V_{i}$ is the volume fraction of each phase, and $E_{i}$ is the elastic modulus of each phase.

In the Voigt upper-limit model (the parallel model), the equivalent strains of each phase are assumed, and the elastic modulus of the composite material is expressed as:

$E_{v}=\sum_{i} V_{i} \cdot E_{i}$

In the Reuss low-limit model (the series model), the equivalent stresses of each phase are assumed, and the elastic modulus is expressed as:

$E_{r}=\left(\sum_{i} \frac{V_{i}}{E_{i}}\right)^{-1}$

where $E_{v}$ and $E_{r}$ are the maximum and minimum elastic moduli of the multiphase composite material, respectively.

\section{Model for Isotropic Two-Phase Composite Material}

For isotropic composite materials, Hill $(1952,1965)$ presented a series and parallel average algorithm:

$E_{\mathrm{eff}}=\frac{1}{2}\left(E_{v}+E_{r}\right)$

However, the Hill average gives no clear physical meanings, and self-consistency is not satisfied.

Following the series model and parallel model, we present a modified model for isotropic two-phase composite materials. In this model, an isotropic element consists of four subelements, as shown in Fig. 1. Each subelement consists of a series mode and a parallel mode in the same volume fractions (phase $1, V_{1}$; phase $2, V_{2}$ and $V_{1}+V_{2}=1$ ). When a load in any direction is applied, the load can be decomposed into horizontal and vertical components; then the elastic moduli in the two directions are equivalent.

The microcharacteristic parameters $\lambda_{v}$ and $\lambda_{r}$ are introduced to represent the fractions of series and parallel modes in the subelement. The two parameters indicate the effect of local heterogeneity in the model. The two parameters are dependent and satisfy $\lambda_{v}+\lambda_{r}=1$, $\lambda_{v} \cdot \lambda_{r} \geq 0$. The formulations of the model are derived at equivalent stress and equivalent strain conditions.

In Fig. 1a, at the equivalent stress condition, i.e., the series mode, the elastic moduli of the two phases are assumed as $E_{1}, E_{2}$, and

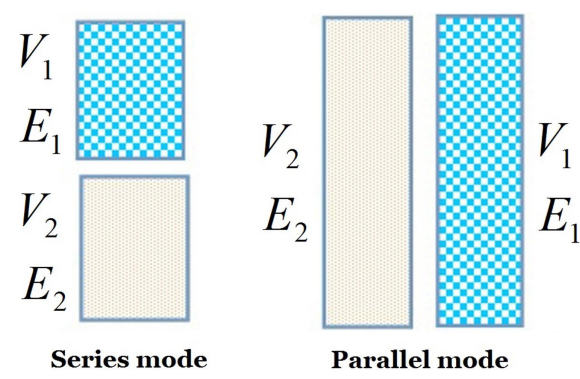

(a) Series and parallel modes

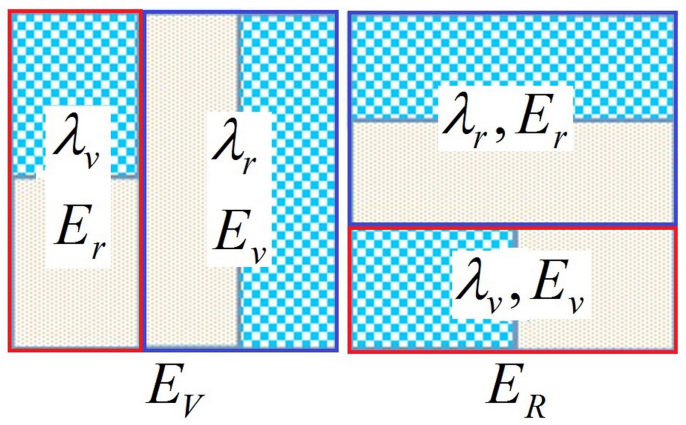

(b) Subelements

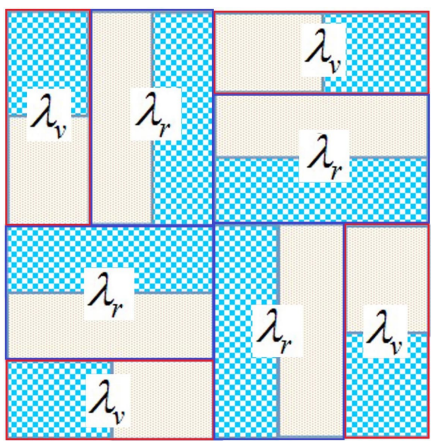

(c) The isotropic element

Fig. 1 Diagram of the model for isotropic two-phase materials

1D elastic deformation is applied. The total deformation equals the sum of the deformation of each phase:

$\frac{\sigma}{E_{r}} \cdot L=\frac{\sigma}{E_{1}} \cdot V_{1} \cdot L+\frac{\sigma}{E_{2}} \cdot V_{2} \cdot L$

Eliminating the length $L$ and the stress $\sigma$,

$E_{r}=\left(\frac{V_{1}}{E_{1}}+\frac{V_{2}}{E_{2}}\right)^{-1}$

At the equivalent strain condition, i.e., the parallel mode, the total stress equals the sum of the stress of each phase:

$E_{v} \cdot \varepsilon \cdot\left(A_{1}+A_{2}\right)=E_{1} \cdot \varepsilon \cdot A_{1}+E_{2} \cdot \varepsilon \cdot A_{2}$

where $A_{1}$ and $A_{2}$ are the areas of phase 1 and phase $2, A_{1} \cdot L=V_{1}$, $A_{2} \cdot L=V_{2}$.

Substituting $A_{1}=V_{1} / L, A_{2}=V_{2} / L$ into Eq. 7 and eliminating the length $L$ and the strain $\varepsilon$ :

$E_{v}=\frac{E_{1} \cdot V_{1}+E_{2} \cdot V_{2}}{V_{1}+V_{2}}=E_{1} \cdot V_{1}+E_{2} \cdot V_{2}$ 
In Fig. 1b, the subelements are composed of series and parallel modes. Then the two modes are regarded as two phases, and the elastic moduli $E_{V}, E_{R}$ of the subelements can be derived from Eqs. 5-8:

$E_{V}=E_{v} \cdot \lambda_{r}+E_{r} \cdot \lambda_{v}$
$E_{R}=\left(\frac{\lambda_{r}}{E_{r}}+\frac{\lambda_{v}}{E_{v}}\right)^{-1}$

In Fig. 1c, due to the central symmetry, the combined mode occupies one-half of the element. Then the total elastic modulus can be expressed as follows:

$E=\left(\frac{1 / 2}{E_{R}}+\frac{1 / 2}{E_{V}}\right)^{-1}$

Substituting Eqs. 9 and 10 into Eq. 11:

$E=\left(\frac{1}{2}\left(\frac{\lambda_{r}}{E_{r}}+\frac{\lambda_{v}}{E_{v}}\right)+\frac{1 / 2}{\lambda_{r} E_{v}+\lambda_{v} E_{r}}\right)^{-1}$

According to the Lagrange limit method, let function $g\left(\lambda_{v}, \lambda_{r}\right)$ be expressed in the following form:

$g\left(\lambda_{r}, \lambda_{v}\right)=\frac{1}{E}+\beta\left(\lambda_{r}+\lambda_{v}-1\right)$
$=\frac{1}{2}\left(\frac{\lambda_{r}}{E_{r}}+\frac{\lambda_{v}}{E_{v}}\right)+\frac{1 / 2}{\lambda_{r} E_{v}+\lambda_{v} E_{r}}+\beta\left(\lambda_{r}+\lambda_{v}-1\right)$

The derivation on $\lambda_{r}, \lambda_{v}$ of Eq. 13 follows:

$\left\{\begin{array}{l}\frac{\partial g\left(\lambda_{r}, \lambda_{v}\right)}{\partial \lambda_{r}}=\frac{1}{2 E_{r}}-\frac{(1 / 2) E_{v}}{\left(\lambda_{r} E_{v}+\lambda_{v} E_{r}\right)^{2}}+\beta=0 \\ \frac{\partial g\left(\lambda_{r}, \lambda_{v}\right)}{\partial \lambda_{v}}=\frac{1}{2 E_{v}}-\frac{(1 / 2) E_{r}}{\left(\lambda_{r} E_{v}+\lambda_{v} E_{r}\right)^{2}}+\beta=0\end{array}\right.$

Combining $\lambda_{v}+\lambda_{r}=1, \lambda_{v} \cdot \lambda_{r} \geq 0$, we can obtain the following two results:

(1) The upper bound of elastic modulus can be obtained at $\lambda_{v} / \lambda_{r}=\left(E_{v} / E_{r}\right)^{1 / 2}$ :

$E_{\max }=\sqrt{E_{v} \cdot E_{r}}$

The physical meaning of the modulus at the upper bound is that the elastic modulus of each subelement equals that of the element. The mathematical meaning is the geometric average of series and parallel modes.

(2) The low bound of elastic modulus can be obtained at $\lambda_{v} \cdot \lambda_{r}=0$ :

$E_{\min }=\frac{2 E_{v} \cdot E_{r}}{E_{v}+E_{r}}$

At the low bound, either the fraction of the series or parallel mode is zero.

The isotropic model could provide a narrower range of elastic modulus than the Voigt upper-limit or Reuss low-limit model when the elastic modulus of each phase has a large difference. Its physical meaning is definite in series and parallel force chains, and the mathematical meaning is the harmonic average of series and parallel modes.

\section{THE ELASTIC MODULUS OF HBS IN TRIAXIAL TESTS}

In this paper, hydrate-bearing sand is considered. Test results of the elastic modulus of HBS are divided into two types: sandy sediment containing gas and hydrate (Case I) and sandy sediment containing water and hydrate (Case II).

For Case I, the tests were conducted using the triaxial system at the Qingdao Institute of Marine Geology; Zhang et al. (2012b) introduced the test apparatus and techniques. The absolute porosity of the sand skeleton $\varphi_{0}$ was 0.48 ; the weight percentages of grains, ranging from 0.3 to $0.5 \mathrm{~mm}$ and from 0.125 to $0.3 \mathrm{~mm}$, were $98 \%$ and $2 \%$, respectively. The test procedures were as follows: first, the sands were filled in the rubber membrane $(0.5 \mathrm{~mm}$ in thickness) as the soil skeleton; a certain volume of water was injected; and methane gas was filled into the pores to the given gas pressure (3-4 MPa). Second, the temperature of the triaxial system was kept at below $2{ }^{\circ} \mathrm{C}$ for two days. During this process, enough gas was supplied to keep the pore pressure constant, and the filled gas volume was recorded. Third, when the instant gas flow was zero and the water was exhausted, the triaxial compression tests with confining pressure of 5-6 MPa were conducted to obtain the stress-strain curves at an effective confining pressure of $2 \mathrm{MPa}$ (the difference between confining pressure and pore gas pressure) and the elastic modulus of HBS in different hydrate saturations. In Table 1, the test-controlling parameters are shown in detail.

The stress-strain curves of HBS in different hydrate saturations are given in Fig. 2. It is shown that the stress increases linearly with the strain initially and keeps constant until the engineering failure strain of $15 \%$ is achieved. It means that the failure modes

\begin{tabular}{lccc}
\hline Cases & $\begin{array}{c}\text { Pore pressure } \\
(\mathrm{MPa})\end{array}$ & $\begin{array}{c}\text { Confining pressure } \\
(\mathrm{MPa})\end{array}$ & $\begin{array}{c}\text { Hydrate } \\
\text { saturation }\end{array}$ \\
\hline 1 & 3.6 & 5.6 & 0 \\
2 & 3.4 & 5.4 & 0.07 \\
3 & 3.7 & 5.7 & 0.15 \\
4 & 3.2 & 5.2 & 0.29 \\
$5-1$ & 3.6 & 5.6 & 0.37 \\
$5-2$ & 3.7 & 5.7 & 0.37 \\
6 & 3.7 & 5.7 & 0.44 \\
$7-1$ & 3.7 & 5.7 & 0.51 \\
$7-2$ & 3.8 & 5.8 & 0.51 \\
$7-3$ & 3.6 & 5.6 & 0.51 \\
\hline
\end{tabular}

Table 1 Test parameters and hydrate saturations of HBS

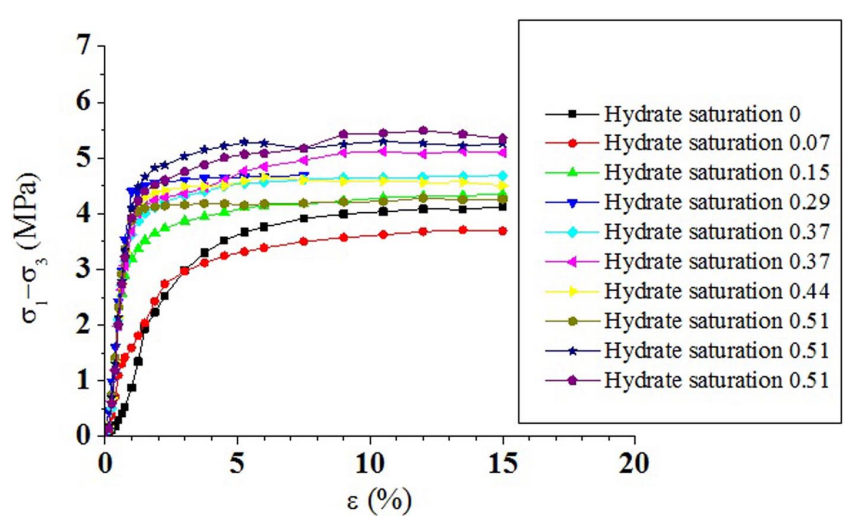

Fig. 2 Stress-strain curves of HBS in different hydrate saturations 


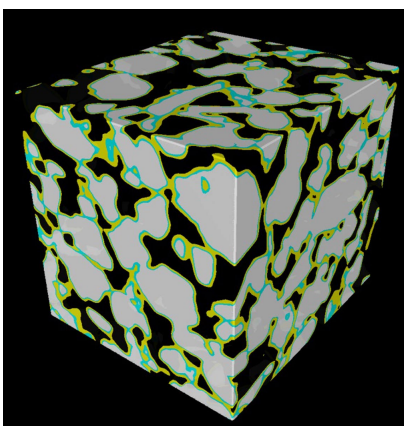

(a) Surface image

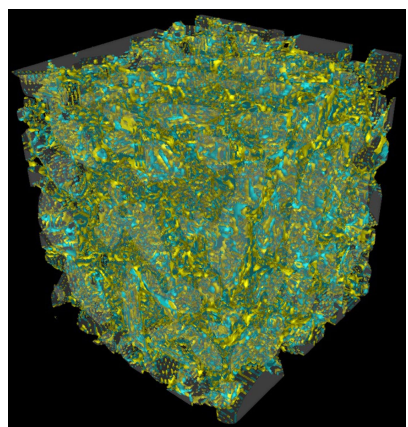

(b) $3 \mathrm{D}$ construction
Fig. 3 3D image of the hydrate occurrence mode (gas, black; water, light blue; hydrate, yellow; sand grain, gray)

are all plastic. The deviatoric stresses $\left(\sigma_{1}-\sigma_{3} ; \sigma_{1}\right.$ is the axial stress and $\sigma_{3}$ is the confining stress) reach approximately 3.6-5.3 $\mathrm{MPa}$ at an effective confining pressure of $2 \mathrm{MPa}$.

Figure 3 presents the X-ray computed tomography (CT) results of the hydrate occurrence mode at the same conditions in the triaxial compression tests. The dimensions of the 3D image are $1.84 \mathrm{~mm}$ in length, $1.63 \mathrm{~mm}$ in width, and $1.70 \mathrm{~mm}$ in height. The X-ray CT introduction can be seen in $\mathrm{Hu}$ et al. (2014). The surface image (Fig. 3a) was provided to give local information of the hydrate occurrence mode of hydrate, while the 3D construction image (Fig. 3b) was reconstructed from sectional images to give information of the fraction and distribution of each phase in HBS. The water is partially filled in the pores of the sediments and adsorbed by the grains. Gas hydrate forms mostly around the grains (hydrate saturation of less than 50\%), and the cohesion among the grains is strengthened.

\section{APPLICATION TO THE ELASTIC MODULUS OF HBS}

HBS contains three phases: soil grains, gas hydrate, and pore fluid. Because the shear modulus of the pore fluid is zero, the soil skeleton and pore fluid are regarded as one phase, and hydrate is regarded as the other phase. The equivalent elastic modulus of the soil skeleton and the pore fluid at a certain excess pore pressure is given first. Then the elastic modulus of HBS is forecasted with the variation of hydrate saturation and hydrate occurrence mode.

Numerical procedures are as follows: First, give the volume fraction of each phase:

$V_{1}=V_{m}+V_{f}, \quad V_{2}=V_{h}, \quad V_{1}+V_{2}=1$

where $V_{m}$ and $V_{f}$ represent the volume fractions of the soil skeleton and pore fluid, respectively.

Second, determine the elastic modulus of each phase: the equivalent elastic modulus of the soil skeleton and the pore fluid by the triaxial compression test is $E_{1}$, the elastic modulus of the hydrate phase is $E_{2}=E_{h}$, and finally, the effective elastic modulus and its range of HBS are forecasted by Eqs. 2, 3, 15, and 16.

\section{Case I: HBS in Gas-Saturated Formation Mode}

Figure 4 presents the comparison of the elastic modulus between tests and theoretical results for Case I. In this study, the secant modulus was calculated at the strain of $2 \%$. The secant moduli are ranged within the geometric average and harmonic average of the series and parallel modes for each phase. The forecasted elastic modulus agrees well with the test results at $\lambda_{v}=\lambda_{r}=0.5$. At this

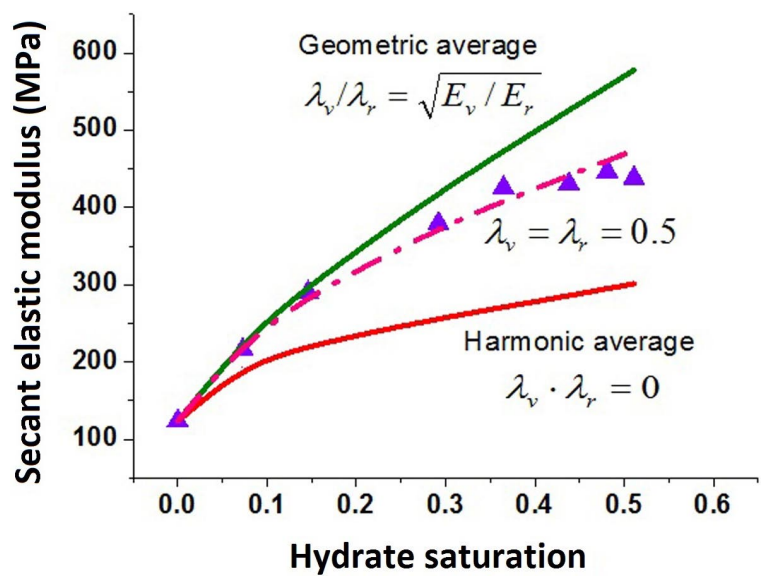

Fig. 4 Comparison between tests and theoretical results for Case I

condition, the prepared material is isotropic and the hydrate in the sediments occurs in a well-distributed mode. Here, the volume fraction of hydrate $V_{h}$ is equal to $\varphi_{0} \cdot S_{h}\left(\varphi_{0} \approx 0.48\right.$ and $S_{h}$ is hydrate saturation). The elastic moduli of the gas-saturated sand and hydrate are $E_{1}=123.3 \mathrm{MPa}$ under the effective confining pressure $2 \mathrm{MPa}$ and $E_{h}=8.2 \mathrm{GPa}$ (Cox, 1983), respectively.

\section{Case II: HBS in Water-Saturated Formation Mode}

The axial compression of Toyoura sandy sediments containing water and hydrate was conducted at drainage condition (Miyazaki et al., 2010, 2011). The initial porosity of the sand skeleton was 0.4 . In the tests, the pore water pressure ranged from 5 to $10 \mathrm{MPa}$, and the effective confining pressures were $1 \mathrm{MPa}, 2 \mathrm{MPa}$, and $3 \mathrm{MPa}$, respectively. The hydrate saturations ranged from $0 \%$ to $60 \%$. The secant modulus $E_{50}$ was adopted instead of the elastic modulus. The secant moduli $E_{1}$ of the soil skeleton and pore water were approximately $261 \mathrm{MPa}, 333 \mathrm{MPa}$, and $376 \mathrm{MPa}$ under the effective confining pressures $1 \mathrm{MPa}, 2 \mathrm{MPa}$, and $3 \mathrm{MPa}$, respectively. The secant modulus increased with the increase of the effective confining pressure and hydrate saturation.

Figure 5 presents the comparison of the elastic modulus between tests and theoretical results for Case II, the elastic modulus of sandy sediments containing water and hydrate distributes in that of the Reuss low-limit model and harmonic average. The elastic modulus of HBS is close to the Reuss low-limit model at low effective confining pressure and hydrate saturation. With the increase of hydrate saturation and effective confining pressure, the elastic modulus trends toward or even exceeds the results of the harmonic average. This means that the hydrate phase occurring in the pore of the sediments trends toward a well-distributed mode in higher soil compression and hydrate filling.

\section{CONCLUSIONS}

Based on the Voigt upper-limit model and Reuss low-limit model for composite materials, a two-phase model of elastic modulus for the isotropic HBS is presented. In the two-phase model, the hydrate saturation and occurrence mode in the pores of the media were considered as one phase, and the soil skeleton and pore fluid were considered as the other phase. A microcharacteristic parameter was introduced to describe a statistical average of the force chains. The upper bound (geometric average) and low bound (harmonic average) were derived. Through the use of the two-phase model, the elastic moduli of HBS obtained in tests were compared with the theoretical results. 


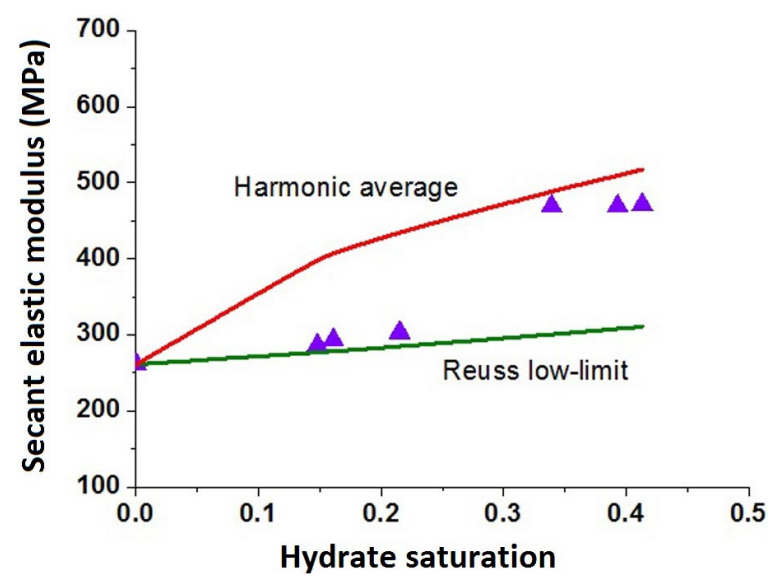

(a) $1 \mathrm{MPa}$

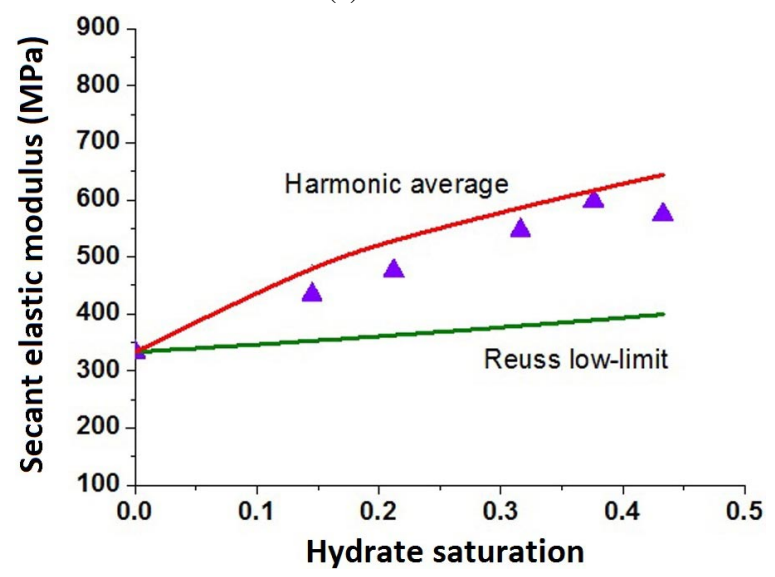

(b) $2 \mathrm{MPa}$

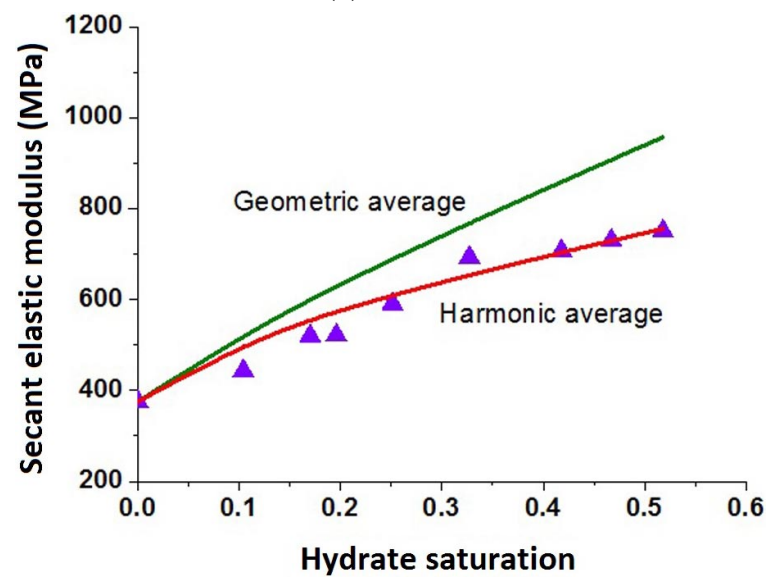

(c) $3 \mathrm{MPa}$

Fig. 5 Comparison between tests and theoretical results for Case II

The isotropic model fits the test elastic modulus of Case I well at $\lambda_{v}=\lambda_{r}=0.5$. The test elastic modulus of Case II distributes in Reuss low-limit and harmonic average, trending toward the harmonic average with the increase of the hydrate saturation and effective confining pressure.

The model presents a new method for forecasting the elastic modulus of HBS. Combining the relationship between the acoustic wave speed and elastic modulus of HBS, we hope that the results provide a reference for the inversion of hydrate saturation from acoustic logging data. The relationship between the microcharacteristic parameter and hydrate occurrence will be considered further.

\section{ACKNOWLEDGEMENTS}

The authors thank Professor Baiyi Wang (English Translation Association) at the Institute of Mechanics, Chinese Academy of Sciences, for revisions of the grammar and editorial errors. This work was supported by the National Natural Science Foundation of China (Grants 41376078, 11072245, and 51239010).

\section{REFERENCES}

Cox, J (Ed) (1983). Natural Gas Hydrates: Properties, Occurrence and Recovery, Butterworth-Heinemann, $136 \mathrm{pp}$.

Dvorkin, J, Prasad, M, Sakai, A, and Lavoie, D (1999). "Elasticity of Marine Sediments: Rock Physics Modeling," Geophys Res Lett, 26(12), 1781-1784. http://dx.doi.org/10.1029/1999GL900332.

Dvorkin, J, Helgerud, MB, Waite, WF, Kirby, SH, and Nur, A (2000). "Introduction to Physical Properties and Elasticity Models," in: Natural Gas Hydrate: In Oceanic and Permafrost Environments, MD Max (Ed), Kluwer Academic, 245-260.

Ecker, C, Dvorkin, J, and Nur, AM (2000). "Estimating the Amount of Gas-Hydrate and Free Gas from Marine Seismic Data," Geophys, 65(2), 565-573. http://dx.doi.org/10.1190/1.1444752.

Hashin, Z (1962). "The Elastic Moduli of Heterogeneous Materials," J Appl Mech, 29(1), 143-150. http://dx.doi.org/10.1115/1.3636446.

Hashin, Z, and Shtrikman, S (1963). "A Variational Approach to the Elastic Behavior of Multiphase Materials," J Mech Phys Solids, 11(2), 127-140. http://dx.doi.org/10.1016/0022-5096(63)90060-7.

Hill, R (1952). "The Elastic Behavior of Crystalline Aggregate," J Proc Phys Soc London, A65, 349-354. http://dx.doi.org/10.1088/0370-1298.

Hill, R (1965). "A Self-Consistent Mechanics of Composite Materials," J Mech Phys Solids, 13(4), 213-222. http://dx.doi.org/10.1016/0022-5096(65)90010-4.

$\mathrm{Hu}, \mathrm{GW}$, et al. (2014). "Observation of Gas Hydrate Distribution in Sediment Pore Space," Chin J Geophys, 57(5), 1675-1682. http://dx.doi.org/10.6038/cjg20140530.

Hyodo, M, Nakata, Y, Yoshimoto, N, and Orense, R (2007). "Shear Behavior of Methane Hydrate-Bearing Sand," Proc 17th Int Offshore Polar Eng Conf, Lisbon, Portugal, ISOPE, 2, 1326-1333.

Hyodo, M, et al. (2013). "Mechanical Behavior of Gas-Saturated Methane Hydrate-Bearing Sediments," J Geophys Res Solid Earth, 118, 5185-5194. http://dx.doi.org/10.1002/2013JB010233.

Lee, MW, and Collett, TS (2006). "Gas Hydrate and Free Gas Saturations Estimated from Velocity Logs on Hydrate Ridge, Offshore Oregon, USA," Proc Ocean Drill Progam Sci Results, College Station, TX, USA, 204, 1-25. http://dx.doi.org/10.2973/odp.proc.sr.204.103.2006.

Lee, MW, Hutchinson, DR, Collett, TS, and Dillon, WP (1996). "Seismic Velocities for Hydrate-Bearing Sediments Using Weighted Equation,” J Geophys Res, 101(B9), 20347-20358. http://dx.doi.org/10.1029/96JB01886.

Masui, A, Miyazaki, K, Haneda, H, Ogata, Y, and Aoki, K (2008). "Mechanical Characteristics of Natural and Artificial Gas Hydrate Bearing Sediments," Proc 6th Int Conf Gas Hydrates, Vancouver, Canada, ICGH, CD-ROM.

Miyazaki, K, Masui, A, Tenma, N, Ogata, Y, and Aoki, K (2010). "Study on Mechanical Behavior for Methane Hydrate Sediment Based on Constant Strain-Rate Test and Unloading-Reloading Test Under Triaxial Compression," Int J Offshore Polar Eng, ISOPE, 20(1), 61-67. 
Miyazaki, K, et al. (2011). "Tri-Axial Compressive Properties of Artificial Methane Hydrate Bearing Sediment," J Geophys Res, 116, B06102. http://dx.doi.org/10.1029/2010JB008049.

Song, YC, Yu, F, Li, YH, Liu, Y, and Zhao, J (2010). "Mechanical Property of Artificial Methane Hydrate Under Triaxial Compression," J Nat Gas Chem, 19(3), 246-250.

http://dx.doi.org/10.1016/S1003-9953(09)60073-6.

Waite, WF, Kneafsey, TJ, Winters, WJ, and Mason, DH (2008). "Physical Property Changes in Hydrate-Bearing Sediment due to Depressurization and Subsequent Repressurization," J Geophys Res, 113(7), 1-37. http://dx.doi.org/10.1029/2007JB005351.

Waite, WF, et al. (2009). "Physical Properties of Hydrate-Bearing Sediments," Rev Geophys, 47(4), 1-38. http://dx.doi.org/10.1029/2008RG000279.

Winters, WJ (1999). "Properties of Samples Containing Natural Gas Hydrate from the JAPEX/JNOC/GSC Mallik 2L-38 Gas Hydrate Research Well, Determined Using Gas Hydrate and Sediment Test Laboratory Instrument (GHASTLI)," Bull Geol Survey Can, 544, 241-250.
Winters, WJ, Pecher, IA, Waite, WF, and Mason, DH (2004). "Physical Properties and Rock Physics Models of Sediment Containing Natural and Laboratory-Formed Methane Gas Hydrate," Am Mineralogist, 89(8-9), 1221-1227.

http://dx.doi.org/10.2138/am-2004-8-909.

Wood, AB (1941). A Textbook of Sound, G Bell and Sons, 610 pp. Yun, TS, Santamarina, JC, and Ruppel, CD (2007). "Mechanical Properties of Sand, Silt, and Clay Containing Tetrahydrofuran Hydrate," J Geophys Res, 112, B04106.

http://dx.doi.org/10.1029/2006JB004484.

Zhang, J, et al. (2012). "Experimental Techniques for Mechanical Properties of Gas Hydrate-Bearing Sediments," Appl Mech Mater, Sanya, China, 275-277, 316-321.

http://dx.doi.org/10.4028/www.scientific.net/AMM.275-277.316.

Zhang, XH, Lu, XB, Zhang, LM, Wang, SY, and Li, QP (2012). "Experimental Study on Mechanical Properties of MethaneHydrate-Bearing Sediments," Acta Mech Sin, 28(5), 1356-1366. http://dx.doi.org/10.1007/s10409-012-0142-3.

\section{The Proceedings of \\ The Twenty-fifth (2015) International OCEAN AND POLAR ENGINEERING CONFERENCE \\ Kona, Hawaii, USA, June 21-26, 2015}

ISBN 978-1-880653-89-0 ISSN 1098-6189

Indexed by Engineering Index, EI Compendex, Scopus and others.

\section{VOLUME I}

FRONTIER ENERGY RESOURCES TECHNOLOGY EOR \& Drilling

OCEAN MINING \& GAS HYDRATES SYMPOSIUM: OMS-2015 (OMGH-2015)

Gas Hydrates, Manganese Nodules \& Crusts, Massive

Sulphide, Deep Ocean Mining and Environment

OFFSHORE WIND AND OCEAN AND ENVIRONMENT

Wind Turbines - Foundations, Support Structures, Floating

Turbines, Analysis \& Testing, Wind \& Wave Loading,

Aerodynamics \& Blades, Installation \& Maintenance, Ocean

and Wind Resources, Hybrid Installation, Tidal \& Current

Energy, OWC, OTEC

ENVIRONMENT SCIENCE AND ENGINEERING

Carbon Capture Sequestration (CCS), Environ Impact \&

Monitoring

OFFSHORE MECHANICS AND OCEAN TECHNOLOGY

OFFSHORE MECHANICS AND OCEAN TECHNOLOGY
Rules And Codes, Subsea, Installation, Decommissioning \&

Installation, Jackup \& Fixed Structures, TLP, SPAR \&

Mooring, Offshore Systems, VLFS \& Floating Structures,

FLNG \& FPSO

ARCTIC SCIENCE \& TECHNOLOGY

Arctic Environment, Arctic Mechanics, Arctic Test Methods, Arctic Operations, Arctic Operations, Arctic Ship Technology, Arctic Structures

\section{VOLUME II}

SUBSEA, PIPELINES, RISERS AND UMBILICALS Pipeline Design, Pipeline Analysis, Installation \& Commission, Riser Design, SCR \& TTRs, Flow Assurance, Lateral Buckling \& Walking, Flexibles \& Umbilicals, Integrity Management,

Test Experiments, Robotics \& Control,

UNDERSEA VEHICLE, COMMUNICATION \& CONTROL

Acoustics \& Imaging, ROV Design \& Navigation, Navigation

\& Control, Oil Spill Tracking \& Control

GEOTECHNICAL ENGINEERING

Computational Geomechanics, Geohazards, Soil Properties, Soil Dynamics, Ground Improvement, Soil-Structure

Interactions, Suction Piles, Offshore Pile Foundation, Anchors, Site Characterization
VOLUME III

\section{HYDRODYNAMICS}

\author{
HYDRODYNAMICS \\ Resistance, Drift \& Wind Forces, Hydroelasticity, Whipping, \\ Stability \& Roll Motion, Fluid-Structure Interactions, Dynamic \\ Positioning Control, NWT, CFD, Shallow Water, MetOcean, \\ Multi-structures, Reliability, Comparative Study \\ TSUNAMI AND SAFETY SYMPOSIUM \\ Generation to Inundation, Tsunami Power, Monitoring \& \\ WLOrning \\ Coupled Sloshing and Ship Dynamics, Liquefaction, Damping, \\ Fluid-Structure Interactions, Design \\ FLOW-INDUCED VIBRATIONS \\ Single Body, Multi-Bodies, Vortex Suppression \\ COASTAL HYDRODYNAMICS \\ Storm Surge, Waves, Lagrangian Particle Methods, Beach \& \\ Estuary, Structures, Port Development
}

\section{VOLUME IV}

HIGH-PERFORMANCE MATERIALS (HPM)

Material Reliability in Petrochemicals, Advanced Materials \& Offshore Structures, Fatigue \& Fracture, Advances in Welding Technology

ARCTIC MATERIALS

Materials Challenges in Arctic, Steel Testing \&

Characteristics, Steel Properties \& Applications

HIGH MANGANESE STEEL SYMPOSIUM

Phase Transform \& Mechanical Properties, Cryogenic

Properties \& Welding

ASSET INTEGRITY

Structural Integrity, Carbon-Based Maintenance, Corrosion Management, Marine Integrity, Pipeline \& Riser Integrity

STRAIN-BASED DESIGN

Keynote, Strain Capacity \& Demand, Pipeline Material Properties, Strain-Based Design and Assessment, Full-Scale Testing, Pipeline Collapse \& Fatigue

RISK, RELIABILITY \& STRENGTH

Slamming \& Hydroelasticity, Product Reliability, Risk

Analysis, Collision \& Impact, System Design

ADVÄNCED SHIP TECHNOLOGY

Green Ship, Hull Form Optimization, Ship Powering, Ship

Hydrodyna mics, Hydrodynamic Loading, Shipbuilding

Simulation, Ultimate Strength, Structures \& Strength,

Transport \& Navigation, Design and Analyses 